\title{
Synthesis of a Fluoro Talc and Attempted Synthesis of Fluoro Chrysotile and Fluoro Anthophyllite
}

\author{
Alvin Van Valkenburg, Jr.
}

\begin{abstract}
As part of a general study of the substitution of fluorine for hydroxyl in silicate structures, it was found that fluorine would partially substitute for hydroxyl in the talc structure. As a result of this substitution it was observed that the $\gamma$ index of refraction was lowered by 0.01 and the temperature of thermal decomposition was raised about $180^{\circ} \mathrm{C}$. Attempts to convert a fluoro talc to a fluoro anthophyllite hydrothermally were not successful. Also fluorine substitution for hydroxyl in chrysotile was not achieved hydrothermally.
\end{abstract}

\section{Introduction}

As part of a general study of the substitution of fluorine for hydroxyl in silicate structures, it was observed that talc $\left(3 \mathrm{MgO} \cdot 4 \mathrm{SiO}_{2} \cdot \mathrm{H}_{2} \mathrm{O}\right)$ readily formed as a reaction product while attempting to synthesize a chrysotile $\left(3 \mathrm{MgO} \cdot 2 \mathrm{SiO}_{2} \cdot 2 \mathrm{H}_{2} \mathrm{O}\right)$ containing fluorine. In those chrysotile experiments in which fluorine was absent from the batch ingredients only an occasional talc grain was detected in the reaction products and this suggested that fluorine might be aiding the formation of talc, possibly substituting for a hydroxyl. A review of the literature indicated that fluorine had never been reported in talc in significant amounts and most chemical analyses omit fluorine determinations entirely. In one reference [1] ${ }^{2}$ talc was found closely associated with a fluorine bearing hydroxyapatite, $3 \mathrm{Ca}_{3} \mathrm{P}_{2} \mathrm{O}_{8} \cdot \mathrm{Ca}(\mathrm{OH}$, $\mathrm{F})_{2}$. However, the chemical analysis showed only trace amounts of fluorine present and the authors concluded that hydroxyapatite had a greater affinity for fluorine than did talc.

The talc hydroxyl is structurally similar to the hydroxyl of the phlogopite micas, $\mathrm{K}_{2} \mathrm{Mg}_{6} \mathrm{Si}_{6} \mathrm{Al}_{2} \mathrm{O}_{20}$ $(\mathrm{F}, \mathrm{OH})_{4}$. Both hydroxyls are located between layered sheets of $\mathrm{SiO}_{4}$ groups and both are bonded to magnesium ions. The two minerals liberate their hydroxyls at temperatures of 800 to $900^{\circ} \mathrm{C}$ at $1 \mathrm{~atm}$ which indicates that the hydroxyl bonding energies are similar. Since the hydroxyls of the phlogopite micas can be substituted entirely by fluorine [2] it appeared reasonable that fluorine might enter the talc structure and a study was instigated to determine the nature of this possible substitution.

\section{Experimental Procedure}

The technique for synthesizing talc was essentially the same as that described by Bowen and Tuttle [3] in which stoichiometric proportions of $\mathrm{MgO}$ and $\mathrm{SiO}_{2}$ were subjected to hydrothermal pressures obtained by using Morey-Ingerson type steel pressure bombs [4] or a Tuttle hydrothermal apparatus [5]. The inner walls of the bombs were lined with platinum to prevent contamination of the ingredients by

\footnotetext{
1 The program of fluorine substitution in hydrous silicates is sponsored by the Office of Naval Research.

${ }_{2}$ Figures in brackets indicate the literature references at the end of this paper.
}

steel and its alloys. In the Tuttle apparatus the batch ingredients were sealed in a platinum cylinder. Distilled water was added to the bombs and platinum cylinders in excess of that needed to satisfy the talc hydroxyl requirements. Batch samples were prepared by thoroughly grinding together the ingredients in a mechanical mortar to insure good mixing and to increase the reactivity of the ingredients by increasing the surface area. Calculated amounts of fluorine were added to the batch in the form of $\mathrm{MgF}_{2}$ to give varying ratios of $\mathrm{F}: \mathrm{OH}$. The reaction products were examined by microscopic, X-ray, and differential thermal analysis techniques, and the data were compared with those of natural tales. Careful examinations were made of the reaction products to detect the presence of $\mathrm{MgF}_{2}$ as its presence in any appreciable amount would indicate that fluorine failed to enter the talc structure. $\mathrm{MgF}_{2}$ has extremely low indices of refraction and can readily be detected microscopically in the presence of talc. The $\mathrm{MgF}_{2}$ introduced into the raw batches had grains of irregular and indistinct outline. In comparison the $\mathrm{MgF}_{2}$ observed in the reaction products of some experiments were well formed needles indicating they were formed as products of recrystallization. This eliminated the doubt that $\mathrm{MgF}_{2}$ observed in reaction products might have resulted from incomplete reaction. Table 1 gives a list of experiments and their reaction products.

TABLE 1. Hydrothermal fluoro-talc synthesis

\begin{tabular}{|c|c|c|c|c|c|}
\hline $\begin{array}{l}\text { Experi- } \\
\text { ment }\end{array}$ & $\begin{array}{l}\text { F sub for } \\
\text { OH in } \\
\text { batch }\end{array}$ & $\begin{array}{l}\text { Temper- } \\
\text { ature }\end{array}$ & $\begin{array}{l}\text { Hydro- } \\
\text { thermal } \\
\text { pressure }\end{array}$ & Time & Major phases \\
\hline $\begin{array}{l}1 \\
2 \\
3 \\
4 \\
5\end{array}$ & $\begin{array}{l}\% \\
25 \\
40 \\
40 \\
40 \\
40\end{array}$ & $\begin{array}{c}{ }^{\circ} C \\
400 \\
400 \\
500 \\
600 \\
700\end{array}$ & $\begin{array}{c}p s i \\
16,000 \\
20,000 \\
18,000 \\
18,000 \\
20,000\end{array}$ & $\begin{array}{c}\text { Hours } \\
72 \\
16 \\
72 \\
72 \\
16\end{array}$ & $\begin{array}{l}\text { Tale a } \\
\text { Do. } \\
\text { Do. } \\
\text { Do. } \\
\text { Do. }\end{array}$ \\
\hline $\begin{array}{r}6 \\
7 \\
5 \\
9 \\
10\end{array}$ & $\begin{array}{l}50 \\
50 \\
50 \\
55 \\
66\end{array}$ & $\begin{array}{l}400 \\
796 \\
808 \\
409 \\
400\end{array}$ & $\begin{array}{l}18,000 \\
16,000 \\
16,000 \\
18,000 \\
16,000\end{array}$ & $\begin{array}{c}72 \\
1 \\
51 / 2 \\
24 \\
120\end{array}$ & $\begin{array}{l}\text { Do. } \\
\text { Do. } \\
\text { Do. } \\
\text { Talc }+\mathrm{MgF}_{2}+\mathrm{SiO}_{2} \\
\text { Do. }\end{array}$ \\
\hline $\begin{array}{l}11 \\
12 \\
13 \\
14 \\
15\end{array}$ & $\begin{array}{r}75 \\
75 \\
75 \\
100 \\
100\end{array}$ & $\begin{array}{l}800 \\
700 \\
410 \\
408 \\
800\end{array}$ & $\begin{array}{l}18,000 \\
20,000 \\
18,000 \\
18,000 \\
18,000\end{array}$ & $\begin{array}{l}60 \\
16 \\
72 \\
96 \\
60\end{array}$ & $\begin{array}{l}\text { Do. } \\
\text { Do. } \\
\text { Do. } \\
\text { Do. } \\
\text { Do. }\end{array}$ \\
\hline
\end{tabular}

a In all cases, the tales mentioned in this table contain fluorine. 


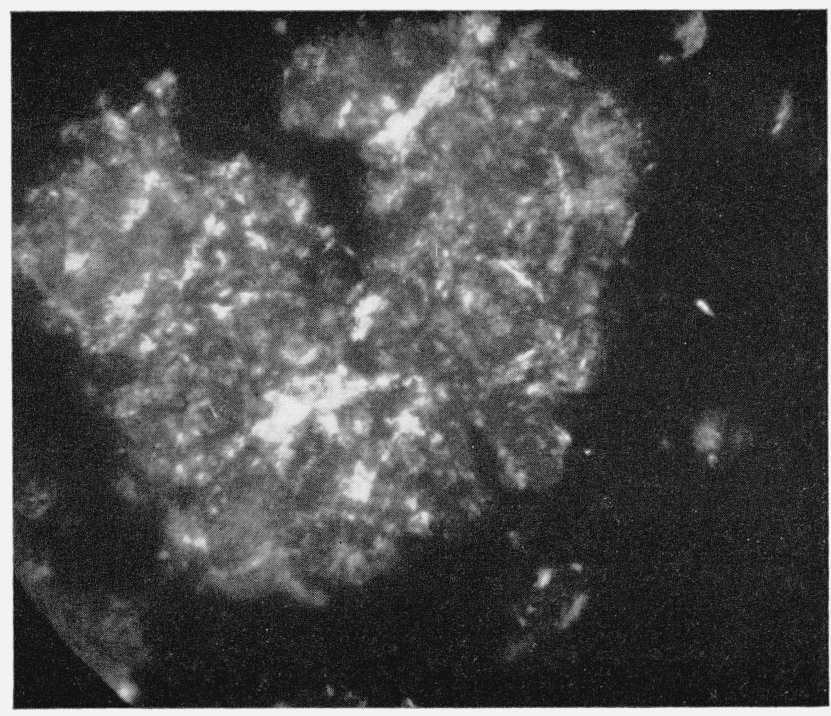

FIgURE 1. Fluoro talc grains showing matted fibers in aggregate form.

Crossed nicols, magnification, $\mathrm{X} 600$.

Talc was the major phase observed in all the experiments prepared in the temperature range from $400^{\circ}$ to $800^{\circ} \mathrm{C}$ and at 16,000 to 20,000 psi. Two general forms of talc were observed, one showing a matted fibrous aggregate in which the fibers appeared to be randomly oriented (fig. 1) and the second showing talc grains with fibers in parallel orientation (fig. 2). In both cases the fibers were extremely fine grained and it was difficult to obtain good optical data.

The refractive indices for pure synthetic hydroxyltalc are approximately $\gamma=1.570$ and $\alpha=1.540$ which correspond to the observations of Yoder [6]. In comparison, the indices of the tales containing the maximum fluorine content (experiments in which $\mathrm{F}: \mathrm{OH}$ was $1: 1$ or greater) were approximately $\gamma=1.560$ and $\alpha=1.540$. As fluorine was substituted for hydroxyl there was a corresponding decrease in the $\gamma$ indices of refraction. This lowering of the $\gamma$ index indicates that fluorine is entering the talc structure. Previously, investigators [7] have established the fact that when fluorine substitutes for hydroxyl there is a lowering of the refractive indices and the amount of lowering is proportional to the fluorine present.

In those experiments where the calculated ratio of $\mathrm{F}: \mathrm{OH}$ was $1: 1$ or less, the major phase was a fluoro talc with an occasional grain of quartz or $\mathrm{MgF}_{2}$ present. However, when the ratio became greater than 1:1, $\mathrm{MgF}_{2}$ was readily observed under the microscope in appreciable quantities. This would indicate that fluorine may be substituted for hydroxyl up to $50 \mathrm{~mol}$ percent.

The X-ray powder patterns of the synthetic fluoro talcs were identical to those of synthetic talcs without fluorine. Unfortunately the powder patterns of the synthetic talcs do not give sharp, clear reflections.

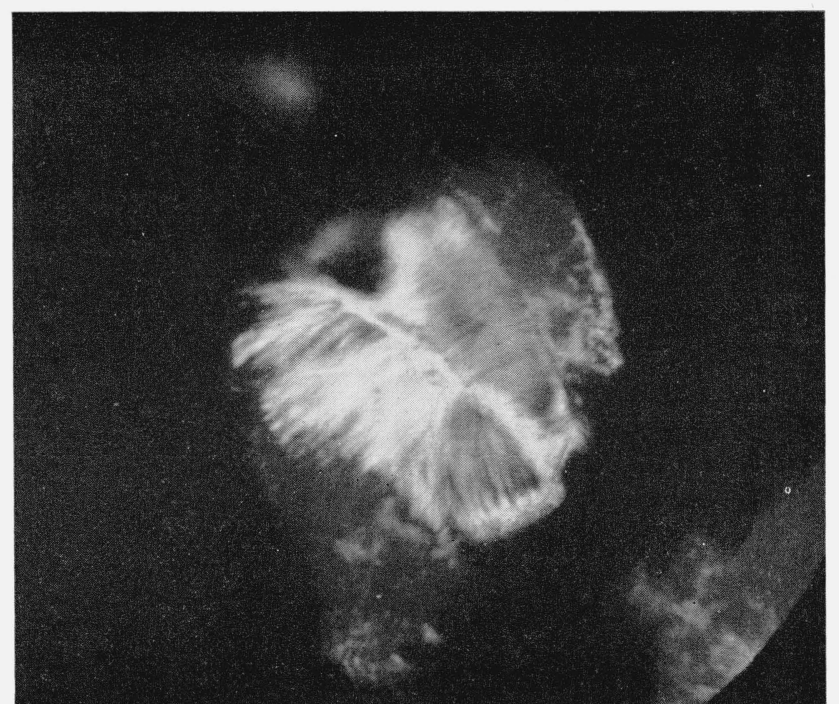

Figure 2. Fluoro talc grain with fibers in parallel orientation.

Crossed nicols, magnification, X 600 .

The diffracted beams are broad and diffuse, characterizing poorly crystallized material.

Differential thermal/analysis studies were made on the fluoro tales, and the results were compared to a synthetic talc without fluorine and to natural talcs. The apparatus used in these studies is similar to that used in other laboratories. A heating and cooling rate of about $12 \mathrm{deg} / \mathrm{min}$ was employed. Curve 1 (fig. 3) contains a typical endothermic reaction peak of a natural talc and it corresponds to the differential thermal analysis curves obtained by Pask and Warner [8]. The endothermic reaction peak at $970^{\circ} \mathrm{C}$ denotes the loss of hydroxyl in the talc. In comparison curve 2 is a typical differential thermal curve for a synthetic talc without fluorine. The general slopes of the two curves are essentially the same. However, their maximum endothermic peaks do not occur at the same temperature and it is believed that the thermal difference may be attributed to a difference in particle size of the two samples. The synthetic talc has extremely fine thread-like masses aggregated into grains and in comparison the natural tales were artificially ground into a powder consisting of platy grains of uniform crystallinity. Curve 3 represents a differential thermal analysis of a synthetic fluoro talc in which the ratio of $\mathrm{F}: \mathrm{OH}$ was calculated to be $1: 1$. The endothermic peak at $100^{\circ} \mathrm{C}$ is believed to be the result of interstitial or surface water escaping from the undried sample just removed from the hydrothermal bomb. The endothermic double peak with maximum intensities at $1,070^{\circ}$ and $1,085^{\circ} \mathrm{C}$ probably represent reactions in which hydroxyl and possibly fluorine were released. The exothermic peak at $1,230^{\circ} \mathrm{C}$ may indicate a recrystallization phenomenon in which $\mathrm{MgF}_{2}$, cristobalite and enstatite are forming. The endothermic peaks occurring at $1,250^{\circ}$ and $1,290^{\circ} \mathrm{C}$ are similar to the endothermic peaks of curve 4 which 


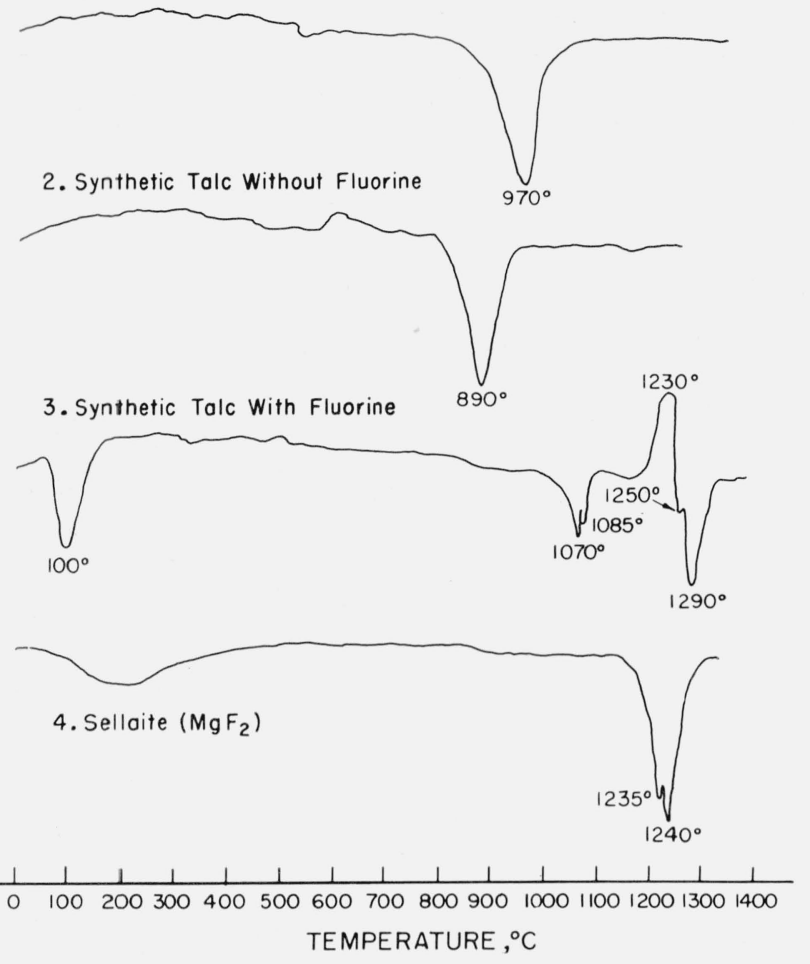

Figure 3. Differential thermal curves.

1, Typical natural talc; 2 , synthetic talc without fluorine; 3 , synthetic talc with fluorine; 4 , sellaite $\left(\mathrm{MgF}_{2}\right)$.

represent a differential thermal curve for $\mathrm{MgF}_{2}$. It is believed that these peaks represent the breakdown of $\mathrm{MgF}_{2}$ with the release of fluorine. A comparison of the endothermic peaks of curves 2 and 3 shows that the fluoro talc has a higher thermal stability than does its hydroxyl analogue. Furthermore, the exothermic peak of curve 3 occurring at $1,230^{\circ} \mathrm{C}$ is lacking in curve 2, indicating that the presence of fluorine alters the course of reaction in the talcs.

Bowen and Tuttle [3] have shown that a synthetic anthophyllite $7 \mathrm{MgO} \cdot 8 \mathrm{SiO}_{2} \cdot \mathrm{H}_{2} \mathrm{O}$ can be synthesized by heating a synthetic talc to $800^{\circ} \mathrm{C}$ with a hydrostatic pressure of $16,000 \mathrm{psi}$ for a period of $1 \mathrm{hr}$. Longer heatings result in the breakdown of anthophyllite into enstatite and cristobalite. This was confirmed in the present investigation. Attempts to convert a fluoro talc into a fluoro anthophyllite were unsuccessful. Samples of fluoro talc were treated hydrothermally for $1 \mathrm{hr}$ and $5 \frac{1}{2} \mathrm{hr}$ at $800^{\circ} \mathrm{C}$ and 16,000 psi. The talc did not appear to have changed in either case as the X-ray and optical data were identical to those of the untreated material.

As stated in the beginning of this paper attempts were made to synthesize a fluoro chrysotile by a process essentially the same as that described for synthetic talc. Stoichiometric proportions of $\mathrm{MgO}$ and $\mathrm{SiO}_{2}$ were sealed in a platinum container with water in excess of that required for formula proportions and a pressure of 16,000 psi and a temperature of $400^{\circ} \mathrm{C}$ were employed. These conditions are within the stability range for synthetic talc [3]. The chrysotile observed under the microscope consisted of irregular masses having low birefringence and a mean index of refraction of these masses was about 1.540. When fluorine in the form of $\mathrm{MgF}_{2}$ was added stoichiometrically to the chrysotile batch there was no apparent lowering of the mean refractive index of the resulting chrysotile. Also the X-ray powder pattern of the chrysotile did not change. These two observations indicates that the hydroxyl in chrysotile does not favor substitution by fluorine.

The author gratefully acknowledges the assistance rendered by G. F. Rynders, R. G. Pike, and others who contributed their time to the project.

\section{References}

[1] L. Mitchell, G. T. Faust, S. B. Hendricks, and D. S. Reynolds, The mineralogy and genesis of hydroxyapatite, Am. Mineralogist 28, 356 (1934).

[2] A. Van Valkenburg and R. G. Pike, The synthesis of mica, J. Research NBS 48, 360 (1952) RP2323.

[3] N. L. Bowen and J. F. Tuttle, The system $\mathrm{MgO}-\mathrm{SiO}_{2}-\mathrm{H}_{2} \mathrm{O}$, Geol. Soc. Amer. 60, 439 (1949).

[4] Morey and Ingerson, Alterations and synthesis of silicates, Econ. Geol. 32, 607 (1937).

[5] John Van Den Heurk, Improved hydrothermal quenching apparatus, Bull. Geol. Soc. Amer. 64, 993 (1953).

[6] American Journal of Science, Bowen Vol., 573 (1952).

[7] N. L. Bowen and J. F. Schairer, Grunerite from Rockport, Mass., and a series of synthetic fluo-amphiboles, Am. Mineralogist 20, 543 (1935).

[8] J. A. Pask and M. F. Warner, J. Am. Ceram. Soc. 37, 126 (1954).

Washington, May 2, 1955. 